\title{
Asset Prices And Asset Quantities*
}

\author{
Monika Piazzesi \\ University of Chicago, \\ CEPR and NBER
}

Martin Schneider

NYU and FRB Minneapolis

October 2006

\begin{abstract}
We propose an organizing framework that determines asset prices by equating household sector asset demand derived from an economic model to the observed supply of assets provided by other sectors. We then use a specific model of household asset demand to decompose historical changes in asset positions into changes in new asset supply and household income, as well as changes in return expectations. Our findings show that supply and income changes are important determinants of the wealth-GDP ratio and real estate positions, while return expectations are the key determinant of equity positions.
\end{abstract}

\footnotetext{
*Email addresses: piazzesi@uchicago.edu, martin.schneider@nyu.edu. The views expressed herein are those of the authors and not necessarily those of the Federal Reserve Bank of Minneapolis or the Federal Reserve System.
} 


\section{Introduction}

Studies that link asset prices to macroeconomic variables make only limited use of data on asset positions. Indeed, one common approach is to characterize the pricing kernel in terms of macroeconomic variables - such as consumption - and then study the properties of asset prices based on the joint distribution of the pricing kernel and asset payoffs. Under this approach, asset quantities are irrelevant. Studies based on business cycle models do consider the quantities of tangible assets, such as physical capital. However, they tend to pay less attention to the evolution of household positions of financial assets.

In this paper, we describe a procedure to empirically implement asset pricing models that lets household sector asset positions take center stage. We consider a sequence of historical trading periods and focus on the three major asset classes owned by US households: corporate equity ("stocks"), residential real estate ("houses"), and nominal fixed income instruments ("bonds"). For each trading period, we use Flow-of-Funds data to measure the new supply of stocks, houses, and bonds provided to households by other sectors such as businesses and the government. We determine household sector asset demand by solving a savings and portfolio choice problem, given household income and asset endowments, as well as expectations. We then find asset prices that equate household asset demand to supply. Under this procedure, the "success" of a model is measured by how well it accounts for the realized series of asset prices and household positions, given the inputs of new supply, income, and expectations.

After discussing the procedure in general terms in Section 2, we illustrate it in Section 3 by implementing a simple model with identical infinitely-lived households. We find that changes in asset supply and aggregate household income can have a significant effect on savings, and hence the ratio of household wealth (at market prices) to GDP. At the same time, these factors matter little for the relative variability of equity and real estate prices. Instead, the model suggests that large observed shifts in household portfolio shares require large changes in stock return expectations. Such changes are consistent with stable real interest rates because stocks are a small share of household sector wealth. Section 4 compares the results to those in Piazzesi and Schneider (2006), which uses the same basic framework but emphasizes the role of demographics for wealth movements and the 
role of inflation for stock return expectations.

\section{Asset Prices and Quantities: An Organizing Framework}

Consider a trading period $t$ during which the household sector trades assets with the rest of the economy - the government, business, and foreign sectors. There are three risky assets. Houses and stocks are long-lived trees that trade at prices $p_{t}^{h}$ and $p_{t}^{s}$, respectively. Nominal bonds are oneperiod assets that trade at a price $q_{t}=\exp \left(-i_{t}\right)$. They are risky because of inflation: their payoff is $\exp \left(-\pi_{t+1}\right)$, where $\pi_{t+1}$ is the inflation rate. At the beginning of trading period $t$, the household sector owns an initial supply of each tree, normalized to one. During the period, the rest of the economy (ROE) sector sells $f_{t}^{h}$ houses, $f_{t}^{s}$ stocks, and fresh bonds worth $D_{t}$ to households. The quantity of new trees may be negative: for example, the ROE sector may repurchase more stocks than it issues. Households earn labor income $y_{t}$ and dividends $d_{t}^{h}$ and $d_{t}^{s}$ on houses and stocks, respectively. They also receive a payoff $\bar{B}_{t}$ on old one-period bonds from the ROE; this payoff should be thought of as principal plus interest.

Households' disposable wealth during the trading period is thus

$$
\bar{w}_{t}=p_{t}^{h}+p_{t}^{s}+d_{t}^{h}+d_{t}^{s}+\bar{B}_{t}+y_{t}=: p_{t}^{h}+p_{t}^{s}+E_{t}
$$

where $E_{t}$ summarizes all (asset and non-asset) income. Households split this wealth into consumption as well as investment in the three assets. Let $s_{t}$ denote the household sector savings rate out of

disposable wealth $\bar{w}_{t}$ and $\alpha_{t}=\left(\alpha_{t}^{h}, \alpha_{t}^{s}, \alpha_{t}^{b}\right)^{\top}$ the vector of portfolio weights. Equating asset demand and asset supply yields

$$
\alpha_{t}^{h} s_{t} \bar{w}_{t}=p_{t}^{h}\left(1+f_{t}^{h}\right) ; \quad \alpha_{t}^{s} s_{t} \bar{w}_{t}=p_{t}^{s}\left(1+f_{t}^{s}\right) ; \quad \alpha_{t}^{b} s_{t} \bar{w}_{t}=D_{t}
$$

So far, equation (2) simply collects accounting identities. All variables can be measured using Flow-of-Funds data, where the identities hold by construction. However, the same identities must be satisfied by an economic model that accounts for household sector asset trading. What such a model 
adds is a description of household decision making, which endogenously derives portfolio weights $\alpha_{t}$ and the savings rate $s_{t}$ as functions of current asset prices and income, as well as expectations of future asset returns and income. Some models add even more structure: they may endogenously determine the decisions of the ROE or how households form expectations.

In this paper, we are interested in model implications for household sector behavior and asset prices. Whatever the precise structure of the model, there is a simple procedure to evaluate those implications empirically for any trading period $t$ : (i) measure income $E_{t}$ and supply $\left(f_{t}^{s}, f_{t}^{h}, D_{t}\right)$ from the Flow-of-Funds accounts, (ii) specify households' return and income expectations, (iii) solve households' savings and portfolio choice problem given current prices, endowments, and expectations, (iv) find asset prices $p_{t}^{s}, p_{t}^{h}$, and $q_{t}$ that solve (1)-(2), where $\alpha_{t}$ and $s_{t}$ are optimal choices determined in step (iii). If the model accounts well for asset prices and household behavior, step (iv) will recover observed asset prices, and the associated optimal choices will match observed savings and portfolio weights.

One interpretation of the above procedure is that it finds a temporary equilibrium in a setting with exogenous asset supply and expectations. Indeed, step (iv) delivers asset prices as functions of three inputs: household income (including asset payoffs), supply, and expectations. This price function can tell us what price movements should occur when some of the inputs change while others are held fixed. The procedure is also informative about models in which the decisions of the ROE sector or household expectations are endogenous. For example, a model with a fully specified business sector gives rise to decision rules for businesses' net issue of equity and dividend payments. If the model accounts well for asset trade between sectors in trading period $t$, then the equilibrium values of $f_{t}^{s}$ and $d_{t}^{s}$ are the same as those measured in step (i) above. The procedure can thus be used to learn about the household side of the model, given equilibrium quantities that must emerge if model-implied trades accord with the data.

Step (ii) of the procedure does not require taking a stand on how expectations are formed. Indeed, the price function can be used to learn about the sensitivity of prices and trades to expectations, and hence to assess various possibilities. In particular, the procedure provides a simple way to assess models that impose rational expectations. Suppose that step (ii) consists of estimating a stochastic 
process for asset prices and income from the data, and forming conditionals. If a rational expectations equilibrium (REE) of the model captures the dynamics of prices well, its price process should be close to the directly estimated process. Step (iv) of the procedure should thus recover observed prices, which should in turn be close to the REE price function evaluated at the state of the model in trading period $t$.

\section{A Simple Model of Household Behavior}

Setup. A large number of identical households lives forever. Their preferences over consumption plans are represented by recursive utility. In particular, the utility of a consumption plan $\left(c_{\tau}\right)_{\tau=t}^{\infty}$ solves

$$
V_{t}=\max \left\{(1-\beta) c_{t}^{1-1 / \sigma}+\beta \mathrm{CE}_{t}\left(V_{t+1}\right)^{1-1 / \sigma}\right\}^{\frac{1}{1-1 / \sigma}}
$$

where $\sigma$ determines the intertemporal elasticity of substitution for deterministic consumption paths and the certainty equivalent is a power function with coefficient of relative risk aversion $\gamma$ for atemporal gambles:

$$
\mathrm{CE}_{t}\left[V_{t+1}\right]=E_{t}\left[V_{t+1}^{1-\gamma}\right]^{\frac{1}{1-\gamma}}
$$

To obtain closed-form solutions for the savings rate and the portfolio weights, we assume that households can trade not only stocks, houses, and nominal bonds, but also riskless one-period bonds and risky claims to future labor income. The riskless rate is denoted $r_{t}$. Trees that pay labor income as dividends trade at a price $p_{t}^{l}$. Households are endowed with one such tree; its value is added to initial disposable wealth $\bar{w}_{t}$ defined in (1). We collect the returns on the four risky assets between $t$ and $t+1$ in a vector $R_{t+1}$. Given initial disposable wealth $\bar{w}_{t}$, households thus face the sequence of budget constraints

$$
\bar{w}_{\tau+1}=R_{\tau+1}^{w}\left(\bar{w}_{\tau}-c_{\tau}\right), \quad R_{\tau+1}^{w}=\hat{\alpha}_{\tau}^{\top} R_{\tau+1}+\left(1-\iota^{\top} \hat{\alpha}_{\tau}\right) \exp \left(r_{\tau}\right)
$$

for $\tau \geq t$, where $\iota$ is a vector of ones and $R_{t+1}^{w}$ is the return on total (human plus nonhuman) wealth, an average of the individual asset returns determined by the vector $\hat{\alpha}_{t}$ of portfolio weights on the 
risky assets.

We assume that households perceive returns on the three trees to be i.i.d. over time, lognormally distributed, and independent of current prices. In contrast, the return on bonds does depend on the current nominal interest rate: households assume that the nominal interest rate $i_{t}$ will remain constant and that inflation is i.i.d. log-normal, so that the return on nominal bonds $R_{t+1}^{b}=$ $\exp \left(i_{t}-\pi_{t+1}\right)$ is also i.i.d. log-normal. We denote the mean of $\log R_{t+1}$ by $\mu=\left(i-\mu_{\pi}, \mu_{-b}\right)^{\top}$, where $\mu_{\pi}$ is expected log inflation and $\mu_{-b}$ is the vector of mean log returns on the three trees. We also denote the variance of $\log$ returns by $\Sigma$. Finally, we assume that the riskless rate $r$ is perceived to be constant.

Optimal decisions. With i.i.d. log-normal returns and homothetic preferences, the optimal savings rate is constant and the optimal portfolio maximizes the certainty equivalent of the return on wealth, $\mathrm{CE}\left(R_{t+1}^{w}\right)$ :

$$
s=\beta^{\sigma} \mathrm{CE}\left(R_{t+1}^{w}\right)^{\sigma-1}, \quad \hat{\alpha} \approx \frac{1}{\gamma} \Sigma^{-1}\left(\mu+\frac{1}{2} \operatorname{diag}(\Sigma)-r\right) .
$$

Portfolio choice on the risky assets thus depends on expected excess returns, relative to the riskless interest rate, while the savings decision depends on the level of returns. The (log) certainty equivalent at the optimal choice can be written as $\log \mathrm{CE}\left(R^{w}\right)=r+\frac{1}{2} \gamma \hat{\alpha}^{\top} \Sigma \hat{\alpha}$.

Equilibrium. As in the previous section, the supply of new houses and stocks is denoted $f^{h}$ and $f^{s}$, respectively, and the supply of bonds is $D$. We also assume that households cannot buy human capital from the $\operatorname{ROE}\left(f^{l}=0\right)$ and that the ROE does not issue riskless bonds. A temporary equilibrium is a collection of prices $\left(p^{h}, p^{s}, p^{l}, r, i\right)$ such that households optimize and markets clear.

Equilibrium household portfolio weights depend on asset supply and income only through the effect of the latter on the riskless interest rate. Indeed, since riskless bonds are in zero net supply, market clearing requires $\hat{\alpha}^{\top} i=1$. From (3), this condition pins down the equilibrium inflation risk premium $i-\mu_{\pi}-r$ as a function of $\mu_{-b}$ and $\Sigma$, both exogenous variables that describe return expectations. Substituting back into (3), we can write the equilibrium weights, $\hat{\alpha}^{*}(r)$ say, as a 
function only of $r$ and exogenous expectations.

Summing up the market clearing conditions, savings $s \bar{w}$ must equal the value of total supply $\sum_{i=h, s, l} p^{i}\left(1+f^{i}\right)+D$. Using the savings rate formula in (3) and expressing prices in terms of equilibrium weights $\alpha^{*}(r)$, we obtain an equation that determines the real interest rate:

$$
\beta^{\sigma} \exp \left\{(\sigma-1)\left(r+\frac{1}{2} \gamma \hat{\alpha}^{*}(r)^{\top} \Sigma \hat{\alpha}^{*}(r)\right)\right\}=\left(\sum_{i=h, s, l} \frac{\hat{\alpha}_{i}^{*}(r)}{1+f^{i}}+\hat{\alpha}_{b}^{*}(r) \frac{E}{D}\right)^{-1} .
$$

Individual tree prices then follow from $p^{i}\left(1+f^{i}\right) / D=\hat{\alpha}_{i}^{*}(r) / \alpha_{b}^{*}(r)$, and nonhuman wealth is equal to $\left(1+\left(\alpha_{h}^{*}(r)+\alpha_{s}^{*}(r)\right) / \alpha_{b}^{*}(r)\right) D$. Holding fixed the value of bonds, an increase in nonhuman wealth must be due to a greater desire to hold long-lived assets relative to bonds, which drives up the prices of the long-lived assets.

Data. We take the length of a trading period to be one year. Data on the three assets come from the Flow-of-Funds accounts - details about measurement and properties of the data are contained in Piazzesi and Schneider (2006). The black line in Figure 1 is the ratio of nonhuman wealth to GDP over our sample period 1952-2002. The darker lines in Figure 2 are household sector equity and residential real estate positions, also stated as a fraction of GDP. In what follows we focus on model implications for these positions. In PS, we consider also price-dividend ratios. Since dividends as a fraction of GDP are much less volatile than asset prices, our results about positions relative to GDP carry over to price-dividend ratios.

The supply of new stocks and houses $f^{s}$ and $f^{h}$, respectively, is measured as net purchases by the household sector divided by market capitalization. The supply of new stocks is mostly stable between $-2 \%$ and $2 \%$, but drops down to $-10 \%$ in the early 1980 s due to repurchases. The supply of new houses is typically between $2 \%$ and $4 \%$; it varies at business cycle frequencies and also exhibits a slight downward trend. We take the supply of bonds $D$ to be the household sector's net position in dollar-denominated instruments, calculated by Doepke and Schneider (2006). It is driven by trends in government and foreign debt, declining roughly from 0.6 GDPs to 0.3 GDPs between 1950 and 1980, rebounding to 0.4 GDPs by 1995 before dropping back to 0.3 GDPs. Finally, total income $E$, which contains the principal of old bonds, is relatively stable around 1 GDP. 


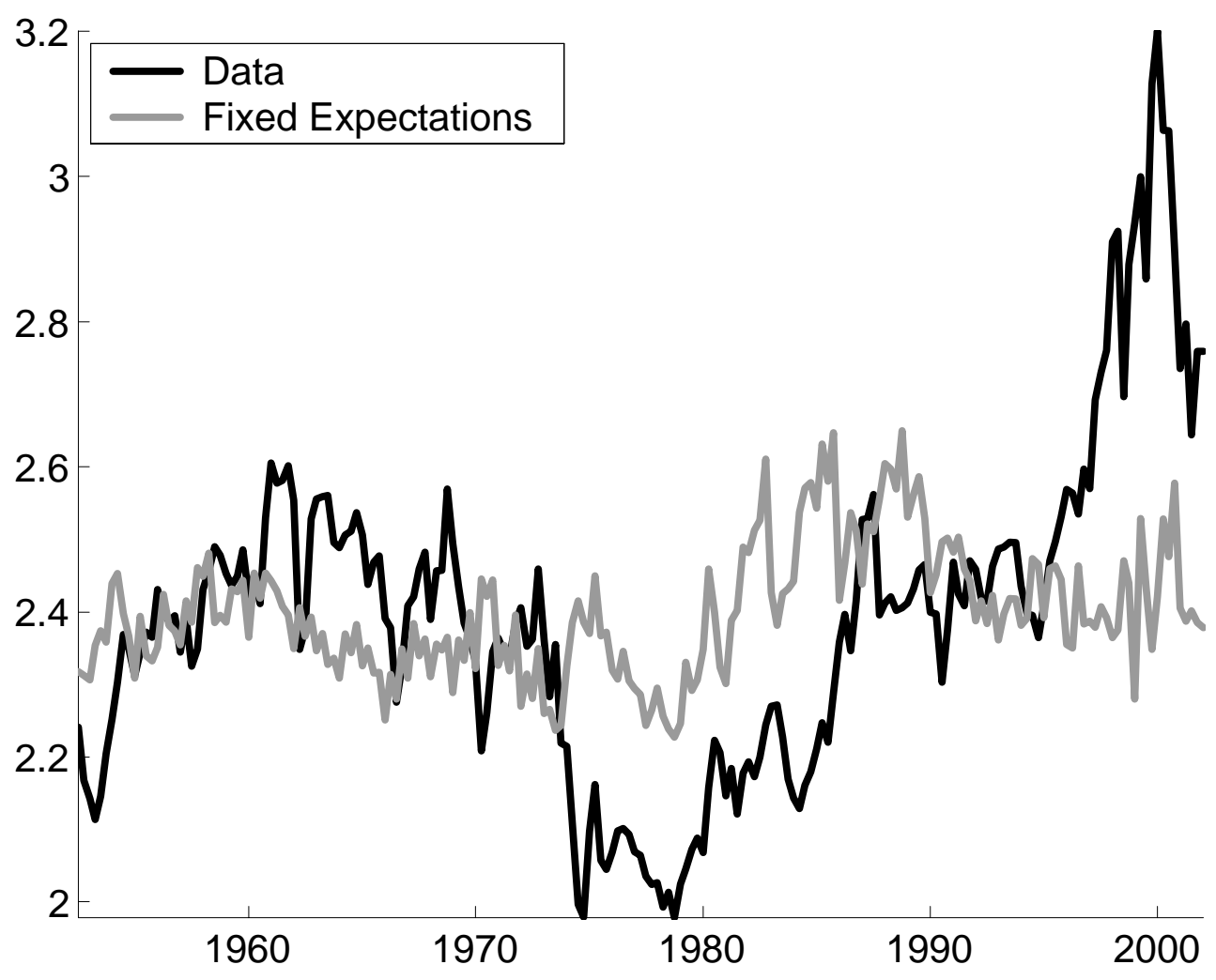

Figure 1: The black line represents aggregate household sector wealth relative to GDP. The gray line represents the wealth-GDP ratio implied by a model with fixed return expectations.

To specify i.i.d. return expectations $(\mu, \Sigma)$, we begin with empirical moments of aggregate returns derived from Flow-of-Funds data. Two issues require special attention. First, households do not invest in a nationally diversified housing index, but rather in individual properties. We therefore add an idiosyncratic shock to the return on housing. Second, the return on human wealth is not observable. We make the common assumption that returns are equal to the growth rate of income. To capture the volatility of the return on human capital faced by a single household, we again add an idiosyncratic shock.

Calibration. To get an idea about orders of magnitudes, we first calibrate the model to postwar averages. In particular, we fix supply and income at their means over our sample 1952-2002. We then select preference parameters and volatilities for the idiosyncratic shocks to match average stock, houses, and bond positions relative to GDP, as well as a $73 \%$ share of human wealth in total wealth. The latter target is consistent with estimates in the literature that range between $70 \%$ and $90 \%$. 


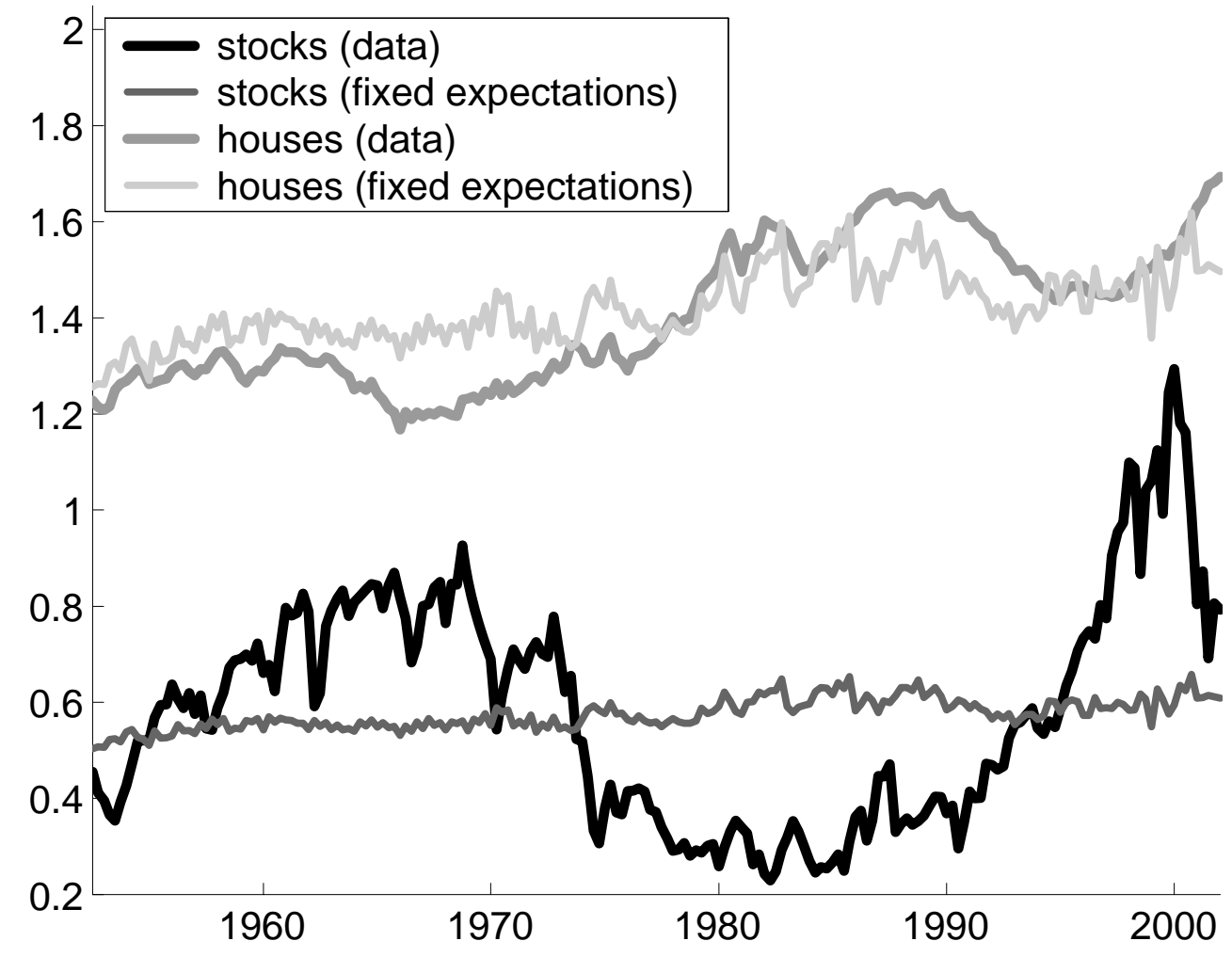

Figure 2: The darker lines represent the value of aggregate housing and stock wealth relative to GDP. The lighter lines represent the same variables implied by a model with fixed return expectations.

Row 1 of Table 1 reports the target statistics.

The benchmark model evaluation in Row 2 uses $\beta=0.89, \sigma=0.5$, and $\gamma=30$. The volatility of housing returns faced by a household turns out to be 3.4 times the aggregate housing return volatility. This is in line with numbers reported in Piazzesi, Schneider, and Tuzel (2006, Appendix C). The volatility of labor income growth is 1.5 times the volatility of aggregate growth. The model also produces reasonable numbers for the real and nominal interest rate, $r=0.66 \%$ and $i=5.14 \%$, although interest rates were not targeted in the calibration.

To understand the comparative statics below, it is helpful to consider how the equilibrium portfolio weights $\hat{\alpha}^{*}(r)$ vary with the riskless rate at the benchmark parameter values. To build intuition, suppose first that returns are independent across assets, that is, $\Sigma$ is diagonal. Equation (3) then implies that for given expected returns $\mu$, the weights on the risky assets fall as the riskless interest rate rises. In particular, the weight on a less risky asset - a closer substitute to the riskless asset 
- falls by more. In equilibrium, the inflation risk premium $\mu_{b}$ adjusts to ensure that $\hat{\alpha}^{\top} \iota=1$. This requires the equilibrium weight on bonds to increase to offset the decline in the other weights. Although returns are correlated at our parameter values, this effect carries over: the bond weight $\alpha_{b}^{*}(r)$ is increasing in $r$ while the equilibrium weights on the three trees are decreasing in $r$.

Comparative statics. We now illustrate the sensitivity of asset values to changes in model inputs. Rows $3-6$ of Table 1 show how asset positions change when $f_{s}, f_{h}, D$, or $E$ increases by one standard deviation. An increase in new asset supply or a drop in income raises the riskless rate and lowers the ratio of nonhuman wealth to GDP. Consider the right-hand side of (4). Mechanically, it is raised by increases in $f$ or $D$ or a decrease in $E$. Since income $E$ is large relative to new asset supply (in particular, $E / D>1+f^{i}$ ), an increase in $r$ then leads to an offsetting drop by inducing a portfolio shift from trees to bonds (the effect on the left-hand side of (4) is quantitatively less important). The portfolio shift in turn is brought about by a drop in the prices of long-lived assets, which lowers the value of nonhuman wealth. At the same time, there is only a small effect on the relative share of stocks versus houses: both assets are relatively risky and thus respond little to changes in the riskless rate.

Rows 7 and 8 report what happens when expected returns on stocks and houses increase by $\sqrt{0.05}$ standard deviations, or $4.2 \%$ and $2.1 \%$, respectively. The scale of these experiments is motivated by typical predictability regressions for stock returns: forecasting of annual stock returns using variables such as the dividend yield typically deliver $R^{2}$ s around $5 \%$, so that the experiment captures a typical movement in such a forecast. Changes in expected returns on stocks or houses lead to large portfolio shifts between these two assets as well as human wealth, while the weight on bonds moves little. At the same time, the riskless rate moves by only a few basis points, an order of magnitude less than the change in expected asset returns. Intuitively, the riskless rate adjusts to bring the savings rate out of total wealth in line with asset supply (cf. (4)). A change in the expected return on the nonhuman asset, a relatively small part of total wealth, does little to affect the overall propensity to save and instead leads only to a portfolio shift. In particular, the ratio of nonhuman wealth to GDP increases as the weight on the more promising nonhuman asset increases.

Sources of Volatility. To assess the role of new asset supply, income, and expectation changes for 
the volatility of asset positions, we now solve the model for every year in the sample. The lighter lines in Figures 1 and 2 show positions that obtain when return expectations $(\mu, \Sigma)$ remain at their benchmark values. With fixed expectations, historical changes in new supply and income are thus large enough to induce sizeable movements in overall wealth as well as in house values. In particular, the negative effect of the drop in bond payoffs due to surprise inflation of the late 1970s (lower $E$ ) and the positive effect of stock repurchases in the early 1980s (lower $f^{s}$ ) are noticeable in Figure 1.

Figure 2 also shows that supply and income changes matter little for the stock market as long as expectations do not change. The simple model considered here thus suggests that stock price movements and the resulting portfolio shifts are due to changes in expectations. One way to see what range of beliefs is required is to hold fixed the conditional variances $\Sigma$ and back out a time series of return forecasts $\left\{\mu_{t}\right\}$ for which the model exactly fits the data on household asset positions. The results suggest large changes in stock return expectations coupled with essentially constant expected real returns on bonds and houses. Backed-out expected stock returns drop from $15 \%$ during the 1960 s boom to $5 \%$ in the early 1980 s and climb back to almost $20 \%$ in the late 1990 s. At the same time, the implied real interest rate is relatively stable: its volatility is $1.2 \%$.

\section{Table 1: Quantitative Results}

\begin{tabular}{lccccccc} 
& $\begin{array}{c}\text { nonhuman } \\
\text { wealth/GDP }\end{array}$ & \multicolumn{2}{c}{ positions/nonhuman wealth } & human wealth/ & real int. \\
& 2.39 & 0.24 & 0.59 & 0.17 & - & - \\
\hline 1. data & 2.39 & 0.24 & 0.59 & 0.17 & 0.73 & 0.66
\end{tabular}

One standard-deviation increase in

\begin{tabular}{lcccccc}
\hline 3. stock supply & 2.34 & 0.24 & 0.59 & 0.17 & 0.73 & 0.67 \\
4. house supply & 2.37 & 0.24 & 0.59 & 0.17 & 0.73 & 0.67 \\
5. bond supply & 2.25 & 0.23 & 0.57 & 0.20 & 0.72 & 0.68 \\
6. income & 2.58 & 0.24 & 0.60 & 0.16 & 0.73 & 0.66 \\
7. exp.stock returns & 2.68 & 0.34 & 0.51 & 0.15 & 0.69 & 0.65 \\
8. exp.house returns & 2.91 & 0.18 & 0.68 & 0.14 & 0.68 & 0.76
\end{tabular}




\section{Conclusion}

Piazzesi and Schneider (2006; PS) apply the procedure outlined in Section 2 to a model with heterogeneous agents. Households differ by age, asset endowments, and beliefs about inflation. They face short sale constraints on stocks and houses, a collateral constraint in the credit market, and a spread between borrowing and lending rates. Houses differ from stocks not only in their payoffs as in the present paper - but also because of tax treatment and because they serve as collateral. To measure the entire distribution of asset endowments, income, and expectations required in a heterogeneous agent model, PS use data from the Survey of Consumer Finances and the Michigan Survey of Consumers.

In PS, we focus on two facts about asset valuation in the 1970s: the dip in the wealth-GDP ratio shown in Figure 1 and the large portfolio shift out of equity into real estate apparent from Figure 2. We attribute the movements in wealth to two effects. The first is a drop in asset income due to surprise inflation. In the present paper, this effect is present via changes in $E$ - for example, it explains why the wealth-GDP ratio drops in the late 1970s under the fixed-expectations scenario plotted in Figure 2. The second effect is demographics: the 1970s saw the entry of baby boomers into asset markets, which created an unusually large share of households with low savings rates.

While demographics and surprise inflation help understand movements in total wealth, the results in PS also suggest that both factors have only small effects on the relative prices of houses and stocks. However, we point out and quantify three channels through which the Great Inflation made stocks less attractive than houses. First, expected inflation lowers the after-tax real return on stocks more than that on housing. Second, disagreement between old lenders and young borrowers about inflation and hence real interest rates - stimulates credit and drives up collateral prices, that is, house prices. The latter is true even if the effect on credit is mitigated by an increase in inflation uncertainty. Finally, low stock return expectations motivated by expected inflation reduce stock prices without moving the nominal interest rate much. Our bottom line is that through these channels inflation is likely to have had a first order effect on asset prices in the 1970s. 


\section{References}

Doepke, Matthias and Martin Schneider 2006. "Inflation and the Redistribution of Nominal Wealth," forthcoming Journal of Political Economy.

Piazzesi, Monika and Martin Schneider 2006. "Inflation and the Price of Real Assets," Working Paper, NYU and University of Chicago.

Piazzesi, Monika, Martin Schneider, and Selale Tuzel 2006. "Housing, Consumption, and Asset Pricing," forthcoming Journal of Financial Economics. 